\title{
Effects of Rainfall Variability on Cassava Yield in Owerri North Local Government Area of Imo State, Nigeria
}

\author{
Anzaku M. Iliyasu ${ }^{1} \quad$ Alkali Mohammed $^{2} \quad$ Buba Y. Alfred $^{4} \quad$ J.I Affi ${ }^{3} \quad$ Garba Umar $^{3}$ \\ 1. School of Continuing Education, Department of Sciences, Bayero University, Kano, Nigeria \\ 2. Department of Environmental Sciences, Nasarawa State University Keffi, Nasarawa State, Nigeria \\ 3. Department of Geography, Nasarawa State University Keffi, Nasarawa State, Nigeria \\ 4. Nigerian Building \& Road Research Institute, 10 NBRRI Road/ I.T. Igbani Street, Jabi District, Abuja, FCT, \\ Nigeria
}

\begin{abstract}
Agriculture in Nigeria is the main source of food and major employer of labour with about $60 \%$ of the Nigerian population engaged in Agriculture. It is predominantly ran-fed and hence vulnerable to climate change. This study assessed the effects of rainfall and temperature variation on cassava in Owerri North Local Government Area of Imo State, Nigeria. Data for the study were collected from the Imo State Agricultural Development Programme for the period of 22years (1995-2017). The data were analyzed statistically and the results revealed that there was minimal variation in rainfall and temperature characteristics, which translates into proportional variability in cassava yield in Owerri North Local Government Area, during the period of study. The study also revealed poor yield with non-significant positive effect of rainfall, maximum and minimum temperature in cassava yield. With reference to the study outcome, it was recommended that weather information should be disseminated to crop farmers to equip them with proper timing, adaptation and mitigation strategies for agricultural practice in the region. This would reduce the adverse effects of climate variability on crop production. Also, it was recommended that since rainfall and temperature do not account for one hundred percent of the determinants of crop yield, other factors such as soil fertility and farm management practices should be explored in order to ensure maximum yield of crops in Owerri, Imo State of Nigeria.
\end{abstract}

Keywords: Effect, Rainfall, Variability, Cassava yield

DOI: $10.7176 / \mathrm{JEES} / 9-3-12$

Publication date:March $31^{\text {st }} 2019$

\subsection{INTRODUCTION}

African countries are particularly vulnerable to climate change because of their dependence on rain-fed agriculture, high levels of poverty, and low levels of human and physical capital, inadequate land distribution and poor infrastructure (Wastonet al.. 1997). Generally, climate change is expected to have mixed effect on agriculture with some areas benefiting from moderate temperature increases and others being negatively affected. Positive effects of climate change could arise from changes in seasons and production cycles. For example, Ethiopia and Southern Africa are expected to have extended growing seasons as a consequence of increased temperature and rainfall, in the same vein, livestock production could be boosted by temperature increases (FAO, 2009). Recent modelling work indicates that the temperature increases by 2100 may be larger than those estimated in 2001 (Stainforthet al., 2005). Temperature and rainfall patterns provide major constraint on primary productivity, which in turn determines secondary productivity for instance cassava growth failure can result if rain does not fall at all under rain-fed agriculture, which can cause erosion and leaching of the soil nutrient leading to low output (BNRCC, 2012).

Agriculture in Nigeria is the main source of food and major employer of labour employing about $60 \%$ of the population. It is predominantly a rain fed system and hence vulnerable to climate change (NFNC. 2003). Dominant crops cultivated in the country include yam, cassava, maize, sorghum, millet, rice and among others. Wisner et al., (2004) reports that the vulnerability of agriculture is not determined by the nature and magnitude of environmental stress like climate change per se. but by the combination of the societal capacity to cope with and/or recover from environmental change. While the society coping capacity and degree of exposure is related to environmental changes, they are both also related to changes in societal aspects such as land use and cultural practices.

Dominant crops cultivated in the country include yam, cassava, maize, sorghum. millet, rice and among others. Cassava is not only a major staple but also a major source of firm income for Nigerian farmers (Nweke, 1996). When compared to other crops, cassava is the most resistant to extreme weather events. It is therefore most often described as a hardy crop and may in this sense be the most adaptable crop to climate variations. Despite the fact that cassava (Manihotesculetacrantz) plant grows and produces well in the Nigeria environment, it has shown different growth behaviour and yield in different years as a result of differences in the annual weather condition (Enete, 2003). This is because climate variability has possibility of degrading soil and water resources and subsequently subsistence agricultural production, which is largely practiced by root and tuber crops farmers (Pidwirny and Sidney. 2007). 
Comparing the output of various crops in Nigeria for the year 2008, cassava production ranks first with 34 million metric tons followed by yam production at 27 million metric tons, sorghum at 7 million metric tons, millet at 6 million metric tons and rice at 5 million metric tons. Nigeria's cassava production is by far the largest in the world, when compared to Brazil Indonesia and Thailand (FAO, 2010). Nigeria's production accounts for 19\% of the world's output and 34\% of Africa's output. Nsoanya and Nenna (2011) noted that the Federal Government of Nigeria has placed much emphasis on cassava production in all the states of the country because of the variety of uses it could he put to Awoyinka (2009) highlighted that in 1999, the Presidential Initiative on Cassava (PIC) strategies was set in motion to achieve, on annual basis, 5 billion US dollars from export of cassava in the next 35 years. The yield of agricultural crops such as cassava are seen to be subjected to daily, monthly and yearly variations, so the production as well as supply of the agricultural product is sometimes inconsistent and does not satisfy demands due to rapid population growth (IPCC 2007). The bulk of climate change studies were conducted in temperate and highly industrialized countries (Mendelson, 2006).

Nigeria's agriculture therefore depends highly on climate because temperature, sunlight, water, relative humidity are the main drivers of crop growth and yield (Nwajuba and Onveneke. 2010). These days. with the rate of rural-urban migration, loss of interest in agriculture by the youths and the scramble for white collar jobs, crop (cassava) yield and production also suffers in Imo State and Nigeria at large.

\subsection{MATERIALS AND METHODS}

Data for this study were source from both the primary and secondary sources. Descriptive statistics such as tables, graphs, frequencies and percentages were used to describe the perception of the respondents. For the purpose of determining the secular trend/variability in temperature and rainfall, the time series was employed. A time series describes the variations in the values of a variable through time. Rainfall and temperature trends, fluctuations were also determined using linear trend analysis with the help of Microsoft Excel. Trend analysis equation is expressed thus, $\mathrm{y}=\mathrm{a}+\mathrm{bt}$.

The linear regression will be used to determine the effect of rainfall and temperature variability on cassava production in the study area. Other statistical methods that will be applied in the analysis of data include the Pearson's Product Moment correlation. This will be used to correlate temperature variability, rainfall variability and cassava production. The analysis will be done using Statistical Package for Social Sciences (SPSS 17).

\subsection{RESULTS AND DISCUSSION}

\subsection{Times Series Trend of Cassava Production in Owerri Local Government Area}

One of the objectives of this study as stated in chapter one was to examine the trend of Cassava yield in Owerri Local Government Area of Imo State. To satisfy this objective, relevant data was obtained by the researchers and presented in table 3.1 .1 below. 
Table 1: Data Presentation of Annual Rainfall, Maximum Temperature, Minimum Temperature and Cassava Yield

\begin{tabular}{|c|c|c|c|c|}
\hline Year & Rainfall (mm) & Max. Temperature & Min. Temperature & Cassava Yield (TON/HA) \\
\hline 1995 & 2622.3 & 382.7 & 22.36 & 7.55 \\
\hline 1996 & 2705.5 & 389.6 & 23.04 & 8.2 \\
\hline 1997 & 2891.4 & 387.3 & 23.47 & 7.88 \\
\hline 1998 & 1640.1 & 397.5 & 23.64 & 7.9 \\
\hline 1999 & 2515.4 & 382.1 & 23.65 & 7.85 \\
\hline 2000 & 2337.2 & 386.1 & 23.63 & 13.24 \\
\hline 2001 & 2304.3 & 388.1 & 23.81 & 12.99 \\
\hline 2002 & 2053.7 & 387.5 & 23.73 & 13.9 \\
\hline 2003 & 2327.8 & 388.4 & 24.13 & 13.76 \\
\hline 2004 & 1762.3 & 388.6 & 28.89 & 14.02 \\
\hline 2005 & 2236.6 & 393.6 & 24.1 & 16.21 \\
\hline 2006 & 3209.1 & 394.2 & 24.3 & 14.18 \\
\hline 2007 & 2361.6 & 380.6 & 22.15 & 14.99 \\
\hline 2008 & 2470.2 & 392.1 & 23.71 & 14.94 \\
\hline 2009 & 2092.8 & 378.4 & 22.65 & 14.91 \\
\hline 2010 & 2865.3 & 391.2 & 26.6 & 15.08 \\
\hline 2011 & 2769.5 & 383.5 & 26 & 15.71 \\
\hline 2012 & 2942.8 & 386.7 & 29 & 14.47 \\
\hline 2013 & 2799.3 & 388.2 & 28.7 & 15.6 \\
\hline 2014 & 13745 & 32.9 & 28.6 & 15.56 \\
\hline 2015 & 1790 & 31.9 & 29.9 & 15.85 \\
\hline 2016 & 1980.5 & 30.5 & 27.8 & 15.9 \\
\hline 2017 & 2015.06 & 31.6 & 28.3 & 15.75 \\
\hline
\end{tabular}

Source: NIMET and ADP, Owerri, Imo State, 2018.

The time series trend of Cassava yield between the years 1995-2017 in the study area was generated from the data presented in the table above and depicted in figure 3.1.1 below.

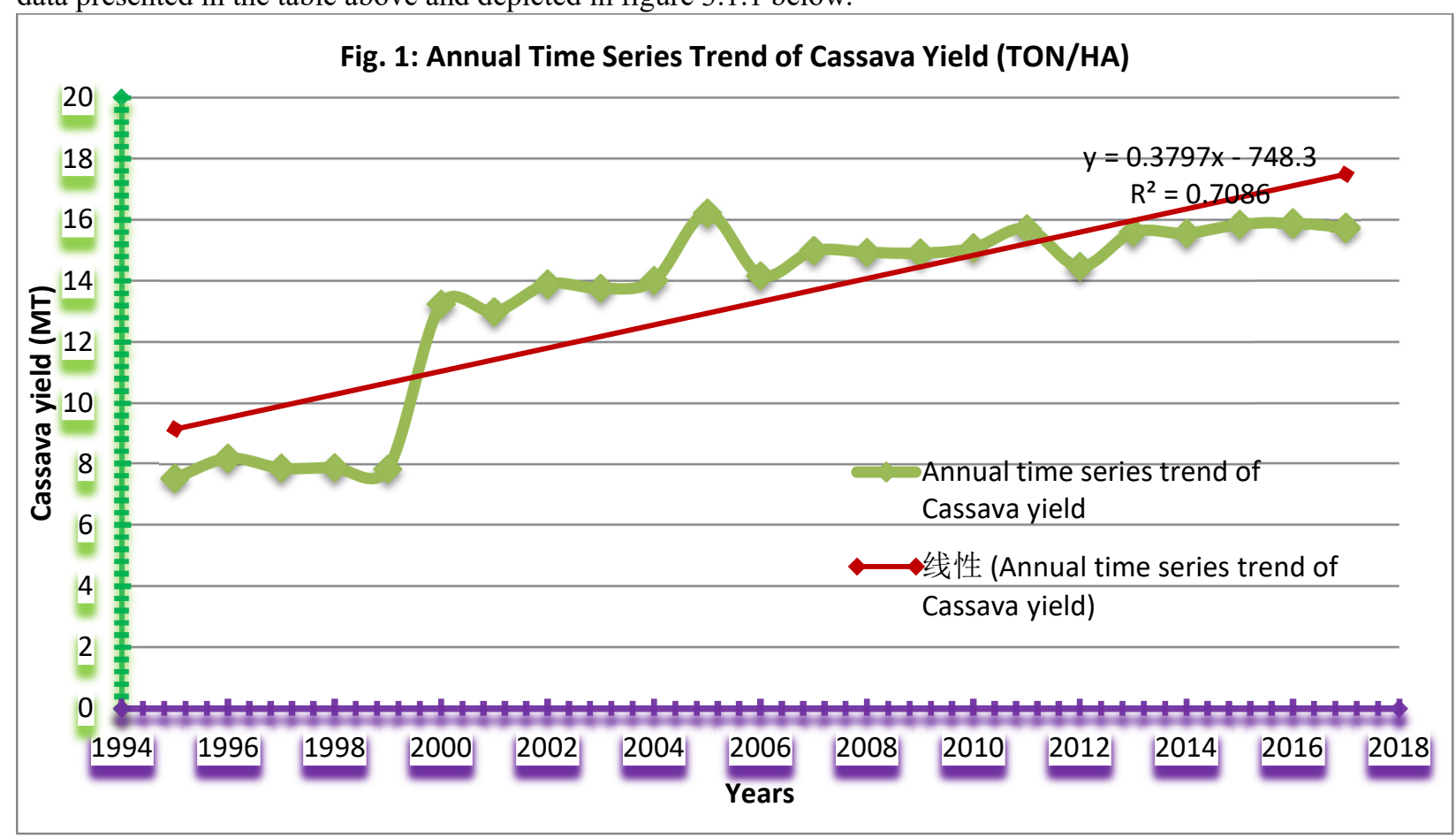

Source: Microsoft Excel trend analysis by authors, 2018.

The time series trend presented in the chart above revels an increasing trend in cassava yield in the study area over the periods under study, as depicted by the trend line. From the trend chart, it can be observed that from the year 1995 to the year 1999, no significant variation was experienced in cassava yield, as 7.55t/ha, 8.2t/ha, 7.88t/ha, $7.9 \mathrm{t} / \mathrm{ha}$ and $7.85 \mathrm{t} / \mathrm{ha}$ were recorded as annual cassava yield in tons per hectare for these years respectively. In year 
2000, a sharp increase in yield was experience, as 13.24t/ha was recorded. A slight decrease in yield was experienced in the year 2001, as 12.99t/ha of cassava was recorded. This decrease in yield was however, only temporal, as the year 2002-2017 experienced increase in yield, compared to the years that precedes them. Although variations in terms of increases and decrease in yield were experienced, it is important to note that these decreases cannot be classified as a significant decrease in yield.

Between the year 2002 to the years 2005, a steady increase in yield was experienced at 13.9t/ha, 13.76t/ha, $14.02 \mathrm{t} /$ ha and 16.21t/ha respectively. Worthy of note here is the fact that the year 2005 recorded the highest yield in cassava in the study area overt entire time frame under consideration in this study. Compared to the year 2005, the year 2006-2009 recorded a decrease in cassava yield, as 14.18t/ha, 14.99t/ha, 14.94t/ha and 14.91t/ha were recorded respectively.

In 2010 and 2011, 15.08t/ha and 15.71t/ha yield was recorded, representing an increase as compared to the 2006 to the year 2009. While, in the year 2012, a decrease in yield was recorded at $14.47 \mathrm{t} / \mathrm{ha}$. A steady increase was experienced from the year 2013-2017 at; 15.6t/ha, 15.56t/ha, 15.85t/ha, 15.9t/ha and 15.75t/ha respectively. Thus, it should be noted the year 1995 recorded the least amount of cassava yield at 7.55t/ha, while the year 2005 recorded the highest amount of cassava yield at 16.21t/ha in the study area, between the years 1995-2017. In the same vein, while the period between the year 1995-1999 can classified as the low yield periods, the periods between the year 2010-2017 can be classified as the peak yield periods.

The trend equation indicates a variation in cassava yield in the study area over the period of time under consideration at $71 \%$ as indicated by the value of $\mathrm{R}^{2}$. This by implication simply implies that there is a significant variation in cassava yield in the study area over the period of time under consideration.

\subsection{Times Series Trend of Annual Rainfall in Owerri Local Government Area}

Figure 1.3.2 below shows the detailed account of the rainfall variability trend in Owerri Local Government Area of Imo State. The trend line shows a fluctuating and gradual decreasing trend annual rainfall in the study area. From the trend chart, it can be observed that there was a gradual increase in annual rainfall in the years 1995,1996 and 1997 at $2622.3 \mathrm{~mm}, 2705.5 \mathrm{~mm}$ and $2891.4 \mathrm{~mm}$ respectively. Compared to these years, the year 1998 recorded a decrease in annual rainfall at $1640.1 \mathrm{~mm}$. This decrease was however short lived, as the years from 1999-2003 recorded an increase in annual rainfall. Although fluctuations were experienced in amount of rain despite being classified as an increase, it is important to state that these fluctuations were rather not significant to be classified as a decrease when compared to the preceding year. Between these years (1999-2003) the following annual rainfall figures were recorded: $2515.4 \mathrm{~mm}, 2337.2 \mathrm{~mm}, 2304.3 \mathrm{~mm}, 2053.7 \mathrm{~mm}$ and $2327.8 \mathrm{~mm}$ respectively.

While a decrease in annual rainfall was experienced in the year 2004 at $1762.3 \mathrm{~mm}$, a steady increase was experienced from the year 2005-2013, with the year 2006 recording the highest annual rainfall in the study area across the entire periods under study. Between these periods (i.e. from 2005-2013) the following amount of annual rainfall were recorded; 2236.6mm, 3209.1mm, 2361.6mm, 2470.2mm, 2092.8mm, 2865.3mm, 2769.5mm, $2942.8 \mathrm{~mm}$ and 2799.3 respectively.

Compared to that of the preceding years of 2005-2013, the year 2014-2016 recorded a decline in annual rainfall at; $1374.5 \mathrm{~mm}, 1790 \mathrm{~mm}$ and $1980.5 \mathrm{~mm}$ respective, while the year 2017 experienced an increase in annual rainfall at $2015.06 \mathrm{~mm}$. Worthy of note here is that that the year 2014 recorded the lowest amount of annual rainfall in Owerri Local Government Area of Imo State across the years 1995-2017, while the year 2006 recorded the highest amount of annual rainfall at $3209.1 \mathrm{~mm}$. The value of $\mathrm{R}^{2}$ in the trend equation indicates a variation in annual rainfall at $04 \%$. The implication here is that if there is no significant increase or decrease, in annual rainfall in the study area across the time frame under study. 


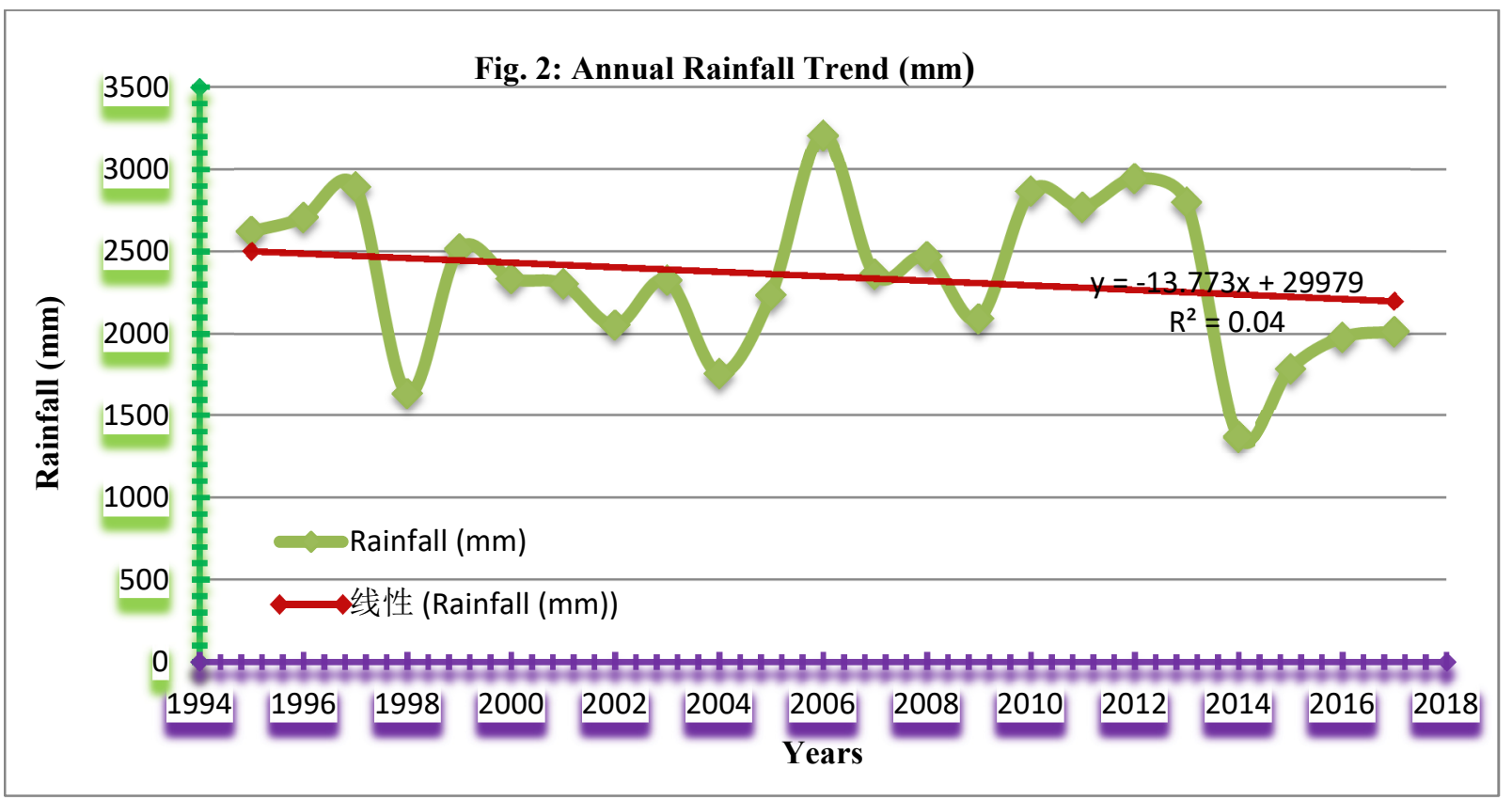

Source: Microsoft Excel trend analysis by authors, 2018.

\subsection{Minimum Temperature in Owerri Local Government Area}

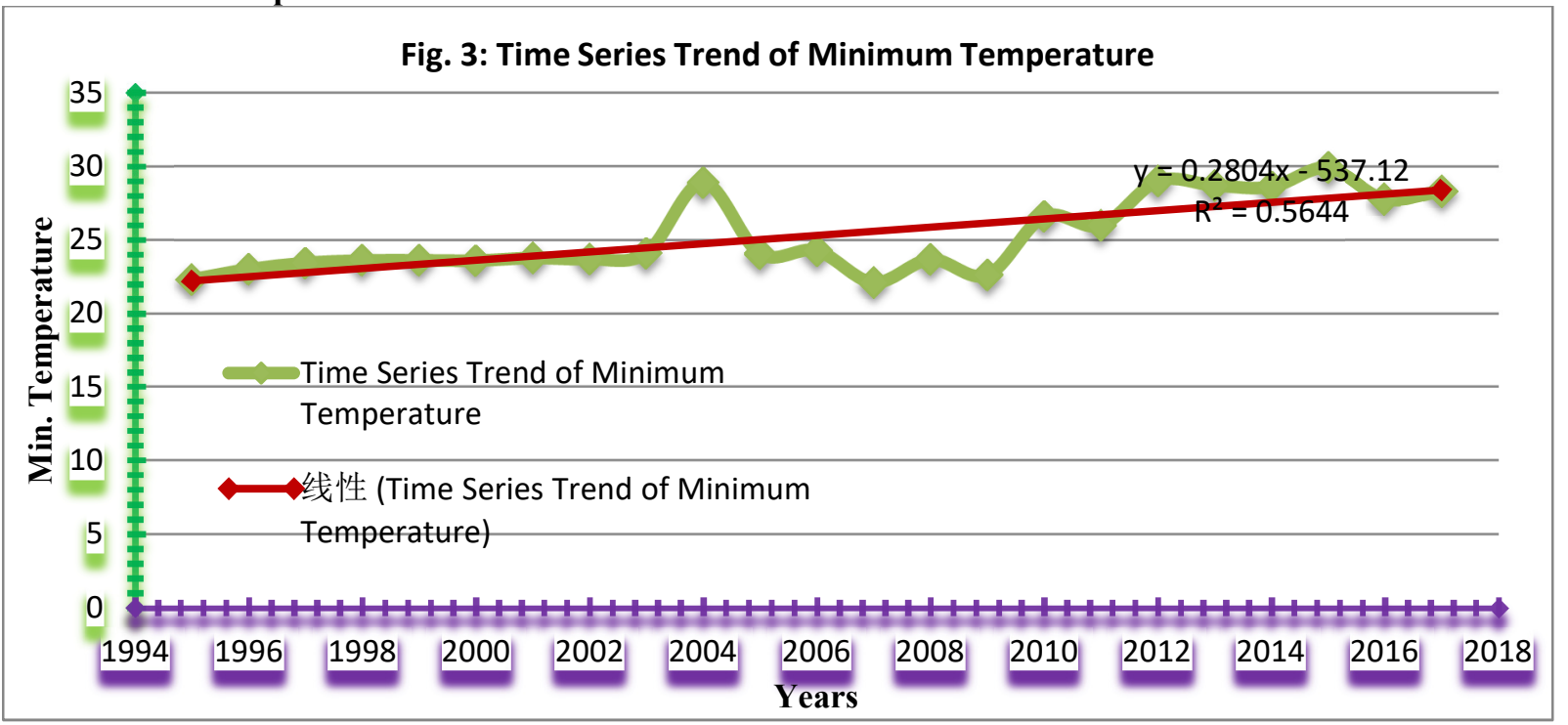

Source: Microsoft Excel trend analysis by authors, 2018.

Figure 1.4.1 depicts the minimum temperature trend in Owerri Local Government Area of Imo State. A careful look shows at the trend plot suggest a gradual increasing trend in minimum temperature in the area of study over the time span. A gradual and steady increase in maximum temperature was recorded within the periods of $1995-2003$ at $22.36^{\circ} \mathrm{c}, 23.04^{\circ} \mathrm{c}, 23.47^{\circ} \mathrm{c}, 23.64^{\circ} \mathrm{c}, 23.65^{\circ} \mathrm{c}, 23.65^{\circ} \mathrm{c}, 23.63^{\circ} \mathrm{c}, 23.81{ }^{\circ} \mathrm{c}, 23.73^{\circ} \mathrm{c}$, and $24.13^{\circ} \mathrm{c}$,respectively. While it can be said that within these preceding years, the year 2003 recorded the highest minimum temperature, it is important to point out that the year 2004 recorded a significant increase in minimum temperature at $28.89^{\circ} \mathrm{c}$.

The chart further reveals a continues decrease in minimum temperature in the study area between the periods of year 2005-2009 while an exponential and steady increase was experienced from the year 2010-2017 at $28.6^{\circ} \mathrm{c}$, $26^{\circ} \mathrm{c}, 29^{\circ} \mathrm{c}, 29.7^{\circ} \mathrm{c}, 28.6^{\circ} \mathrm{c}, 29.9^{\circ} \mathrm{c}, 27.8^{\circ} \mathrm{c}$ and $28.14^{\circ} \mathrm{c}$ respectively, it however important to note that within the time span under study, the year 2015 recorded the highest level of minimum temperature in the study area at $29.9^{\circ} \mathrm{c}$. The trend equation indicates the level of variation in minimum temperature in the study area at $56 \%$ as indicated by the value of the $\mathrm{R}^{2}$. The implication hers is that an increase in minimum temperature to crop will affect photosynthetic activities of crops which may in the long run affect the yield of crops. 


\subsection{Maximum Temperature in Owerri Local Government Area}

The trend of annual maximum temperature of the study area across the time frame under consideration was also established so as to ascertain the variability in maximum temperature. The downward slope of the trend line here indicates a decreasing trend in maximum temperature in the area of study over the time span under consideration. If we critically observe time series plot from the year 1995-2013, it will be noted that the plot is an almost perfect parallel plot, implying an almost insignificant variation in maximum temperature within these period. In the year 2014 , a steep decline in maximum temperature was experienced at $32.9^{\circ} \mathrm{c}$. The decline was accompanied by a further decline in maximum temperature in the year 2015,2016 and 2017 at $31.9^{\circ} \mathrm{c}, 30.5^{\circ} \mathrm{c}$ and $31.6^{\circ} \mathrm{c}$ respectively. The time series trend also reviles that the year 1998 recorded the highest maximum temperature, at $397.5^{\circ} \mathrm{c}$, while the year 2016 recorded the lowest maximum temperature in the study area at $30.5^{\circ} \mathrm{c}$. The R2 value of 0.433 in the trend equation hence imply that there was $43 \%$ variation in maximum temperature in the study area over the periods under consideration.

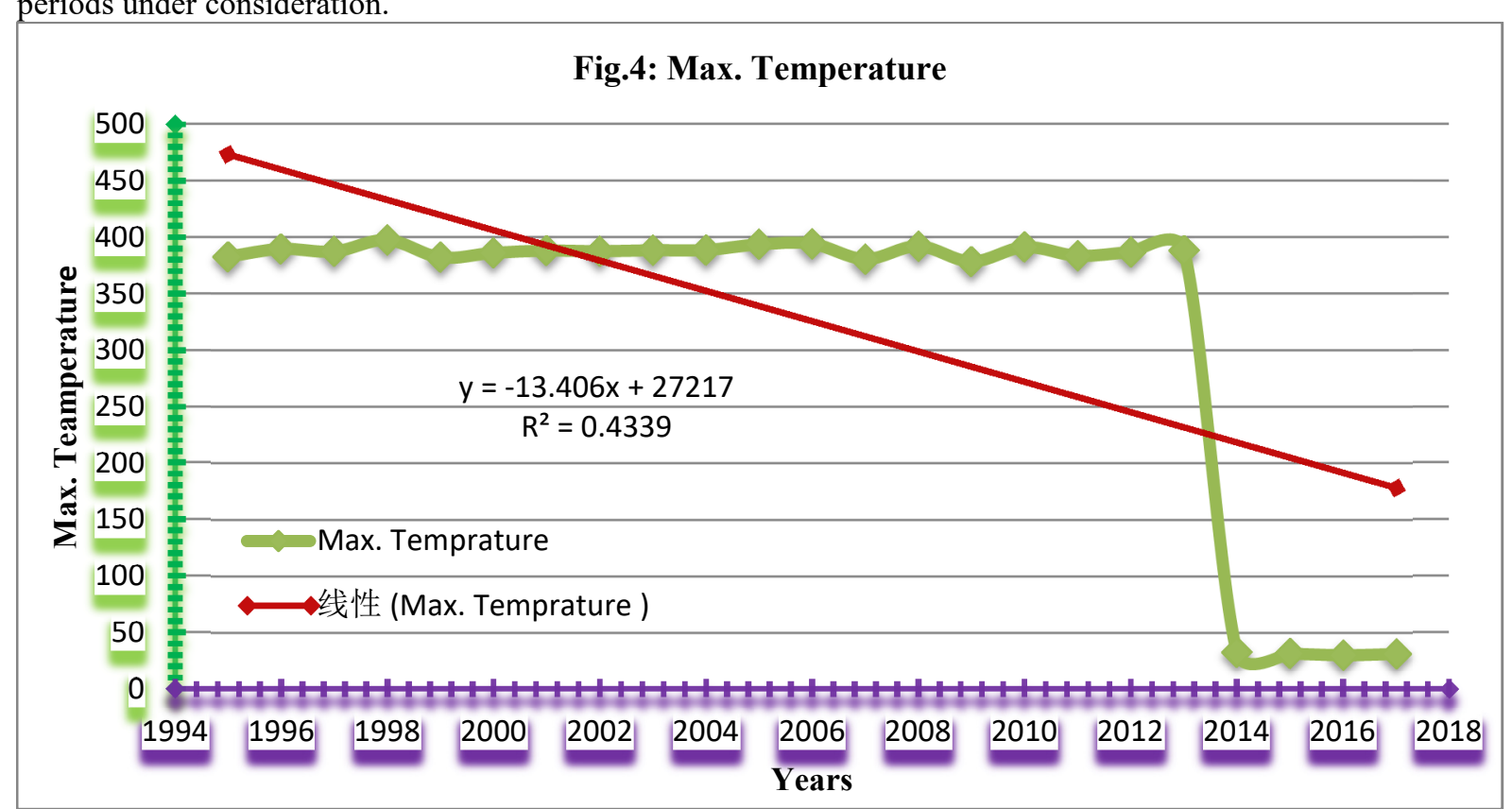

Source: Microsoft Excel trend analysis by authors, 2018.

3.4 Relationship between Cassava Yield, Rainfall, Maximum Temperature and Minimum Temperature in Owerri Local Government Area of Imo State

Table 1: Correlation Analysis of Rainfall, Temperature and Cassava Yield

\begin{tabular}{c|c|c|c}
\hline Cassava yield (t/ha) & $\begin{array}{c}\text { Rainfall } \\
(\mathrm{mm})\end{array}$ & Max. Temperature $\left(\mathrm{T}^{\circ} \mathrm{c}\right)$ & Min. Temperature $\left(\mathrm{T}^{\circ} \mathrm{c}\right)$ \\
\hline $\begin{array}{c}-0.175 \\
\text { Sig. (2-tailed) } 0.424\end{array}$ & $\begin{array}{c}1 \\
\text { Sig. (2-tailed) }\end{array}$ & $\begin{array}{c}0.561^{* *} \\
\text { Sig. (2-tailed) } 0.005\end{array}$ & $\begin{array}{c}0.151 \\
\text { Sig. (2-tailed) } 0.248\end{array}$ \\
\hline
\end{tabular}

Source: SPSS version 17 Pearson Product Moment Correlation analysis, 2018.

The relation between rainfall, temperature and sampled crop was examined through the Pearson Product Moment Correlation and a two tail test employed. By definition, correlation is simply the degree of relationship that exists between two or more variables. In interpreting the correlation results i.e. the various strength of a correlation or relation, the following should be noted:

$>$ At exactly -1 : there is perfect negative linear relationship

$>$-0.70: there is a strong negative linear relationship

$>$-0.50: there is a moderate negative linear relationship

$>-0.30$ : there is a weak negative linear relationship

$>$ At exactly 0: there is no linear relationship

$>\quad+0.30$ : there is a weak positive linear relationship

$>\quad+0.50$ : there is a moderate positive linear relationship

$>\quad+0.70$ : there is a strong positive linear relationship

$>$ At exactly +1 : there is a perfect positive linear relationship

The correlation analysis as shown by the correlation coefficient result extract in table 4.2 above depicts the 
various degrees of relationships. The correlation coefficient between Cassava yield and rainfall, maximum and minimum temperature was arrived at -0.175 . By interpretation, this simply means that there a weak negative linear correlation (relationship) between cassava yield and the rest of the variables under consideration (i.e. rainfall, maximum temperature and minimum temperature). With a significant value of 0.424 , which is far greater than 0.01 level of significance, the researcher thus concluded there is no significant relationship between cassava yield and rainfall, maximum and minimum temperature in the study area, across the time period under consideration of the study, (1995-2017).

With respect to relationship that exists between rainfall and cassava yield, maximum temperature and minimum temperature, a correlation coefficient of 1 was arrived at. This by interpretation implies a perfect positive linear relationship between rainfall and these variables (i.e. cassava yield, maximum and minimum temperature).

The correlation analysis also tested the relationship that exists between maximum temperature and rainfall, minimum temperature and cassava yield over the time span under investigation. A correlation coefficient of 0.561 was arrived at. The result here by interpretation, implies that there is a moderate positive linear relationship these variables. With significant value of 0.005 , which is below the acceptable significant value of 0.01 , the researcher thus concluded that there is a significant relationship between maximum temperature and cassava yield, rainfall and minimum temperature.

In the same vein, the relationship between minimum temperature and the other three variables under study (rainfall, maximum temperature and Cassava yield) was also tested, and a correlation coefficient of 0.151 was arrived at, which also implies a weak positive linear relationship between these variables (i.e. rainfall, cassava yield and maximum). With significant value of 0.248 , which is above the acceptable significant value of 0.01 , the researcher thus concluded that there is no significant relationship between minimum temperature and cassava yield, rainfall and maximum temperature.

\subsection{Effect of Rainfall and Temperature Variability on Cassava Yield in Owerri Local Government Area of Imo State}

In order to evaluate the effects of rainfall and temperature variability on Cassava yield in Owerri Local Government Area of Imo State, a linear regression analysis was carried out. Regression analysis by definition is a set of statistical processes for estimating the relationships among variables. A regression analysis was employed because it helps one understand how the typical value of the dependent variable (or criterion variable) changes when any one of the independent variables is varied, while the other independent variables are held constant.

Table 1.4.4: Regression Analysis of Rainfall, Temperature and Crop yield

\begin{tabular}{|c|c|c|c|c|c|c|c|c|c|}
\hline \multirow[t]{2}{*}{ Variables } & \multirow{2}{*}{$\begin{array}{c}\text { R- } \\
\text { Square } \\
\left(\mathrm{r}^{2}\right)\end{array}$} & \multirow{2}{*}{$\begin{array}{c}\text { Adjusted } \\
\text { R } \\
\text { Square } \\
\left(\bar{R}^{2}\right)\end{array}$} & \multicolumn{2}{|c|}{$\begin{array}{l}\text { Unstandardized } \\
\text { Coefficients }\end{array}$} & $\begin{array}{c}\text { Standardized } \\
\text { Coefficients }\end{array}$ & \multirow[t]{2}{*}{$\mathrm{t}$} & \multirow[t]{2}{*}{ Sig. } & \multirow[t]{2}{*}{$\mathrm{F}$} & \multirow[t]{2}{*}{ Sig } \\
\hline & & & B & Std. Error & Beta & & & & \\
\hline Constant & \multirow[t]{4}{*}{0.535} & \multirow[t]{4}{*}{0.174} & -0.847 & 8.846 & & -0.096 & 0.237 & \multirow[t]{4}{*}{2.545} & \multirow[t]{4}{*}{0.087} \\
\hline Rainfall & & & 0.000 & 0.002 & -0.016 & -0.066 & 0.775 & & \\
\hline $\begin{array}{c}\text { Max. } \\
\text { Temperature }\end{array}$ & & & -0.001 & 0.006 & -0.006 & -0.231 & 0.552 & & \\
\hline $\begin{array}{c}\text { Min. } \\
\text { Temperature }\end{array}$ & & & 0.588 & 0.300 & 0.300 & 1.963 & 0.495 & & \\
\hline
\end{tabular}

Source: SPSS version 17 linear regression analysis, 2018.

The result extract in table 1.4.4 depicts the effect of the variation in rainfall and temperature on cassava yield in the area of study. The coefficient of determination (also known as the R-Square $\mathrm{R}^{2}$ ) by definition is the proportion of the variance in the dependent variable (Cassava yield in this case), that is predictable from the independent variable(s) (Rainfall, Maximum and Minimum Temperature), was arrived at 0.535 . This thus implies that $54 \%$ of the variation in Cassava yield is explained by the variation in rainfall, minimum and maximum temperature between the periods of 1995-2017 in Owerri Local Government Area of Imo State.

The use of the adjusted $\mathrm{R}^{2}$ is an attempt to take account of the phenomenon of the $\mathrm{R}^{2}$ automatically and spuriously increasing when extra explanatory variables are added to the model. It is a modification due to Henri Theil (1961) $\mathrm{R}^{2}$ of that adjusts for the number of explanatory terms in a model relative to the number of data points. The adjusted $\mathrm{R}^{2}$ can be negative, and its value will always be less than or equal to that of $\mathrm{R}^{2}$. Unlike $\mathrm{R}^{2}$, the adjusted $\mathrm{R}^{2}$ increases only when the increase in $\mathrm{R}^{2}$ (due to the inclusion of a new explanatory variable) is more than one would expect to see by chance.

In other words, the adjusted coefficient of determination $\left(\mathrm{R}^{2}\right)$ is taken into consideration when the degree of freedom increases or decrease. This is to correct the defect of the inclusion of additional explanatory variables in the initial function. From the result extract of the regression analysis, the $\overline{\mathrm{R}}^{2}$ was arrived at 0.174 . This by 
implication implies that over $17 \%$ of the total variation in cassava yield is explained by the variation in the explanatory variable (rainfall, maximum and minimum temperature) after taking into consideration the degree of freedom (19) which is indeed strong (see appendix for degree of freedom).

The regression result shows the Student t-statistics for rainfall at -0.066 , with a significant value of 0.948 . Thus, the null hypothesis which states that there is no significant increase in the patter rainfall was tested at $0.05 \%$ level of significance.

\subsection{CONCLUSION}

The study revealed that there is a minimal variability in rainfall and temperature characteristics, which translates into proportional variability in cassava yield in Owerri Local Government Area. Data were collected for a period of twenty-two (22) years from the Nigeria Metrological Agency and Agricultural Development Programme, Owerri, Imo State. The data were analyzed using correlation and regression analysis with the aid of the SPSS statistics package version 25, while the trend function was done with the aid of Microsoft Excel. The result shows an increase in minimum temperature, decrease in maximum temperature and rainfall distribution over the investigated period.

\section{REFERENCES}

1. Adejuwon, S. A. (2004). Impact of Climate Variability and Change on Crop yield in Nigeria.Lead Paper Presented at the Stakeholders Workshop on Assessment of Impacts andAdaptation to Climate Change Held at the Conference Centre, ObafemiAwolowoUniversity Ile-Ife Osun State, Nigeria 20-21 September.

2. Ado, S.G. and Asiribo, O.E. (1989).Influence of Weather Variables on Pepper Fruit Yield in the Nigerian Savannah. Proceedings of Conference on Climate Change and Agriculture, Lagos, Kola Okanlawon Publishers Ltd.

3. Ama EQ. and Adejuwon S.A. (1994) Regional Climate Change: Implication on Energy Production in the Tropical Environment. A Paper Presented at the International Workshop on the Impact of Global Climate Change on Energy Development, Lagos.

4. Akpalu, W., Hassan, RM., Ringler C. (2008) Climate Variability and Maize Yield in South Africa. http://www.ifpri.Org/publication/clirnatevariability-and-maize-yields

5. Allen. R.G. and Rosen weigh, C. (1991) $\mathrm{CO}_{2}$-induced Climate Changes and Irrigation — Water Requirements. Journal of Water Resources Planning and Management, Vol. 117, No.2, pp. 157-178.

6. Anikwe, M. A. N, \& M. E. Obi. (1999). Evaluation of an index model for quantifying the productivity of soils in South-eastern Nigeria using maize as a test crop. Journal of Agriculture and Environment, 1, 80-89.

7. Anyaegbunarn H.N., Nto P.O., Okoye B.C. and Madu T.U. (2011). Analysis of Determinants of Farm Size Productivity among Small- Holder Cassava Farmers in South East Agro Ecological Zone, Nigeria American Journal of Experimental Agriculture 2(1): 74-80, 2012 SC ENCEDOMAIN international www.sciencedomnaui.org

8. Appale. T.G., Ogunyinka A., Sanusi, RA., and Ogunwande S. (2010). Effects of Global Climate Change on Nigerian Agriculture: An Empirical Analysis, No 91751, $84^{\text {th }}$ Annual conference ofAgricultural Economics Society. Edinburgh, Scotland.

9. Atayi, E.A. and Knipscheer, H.C. (1980).Survey of Food Crop Farming Systems in the "ZAPI-EST" East Cameroon JITA/ONAREST. pp.62

10. Awoyinka Y.A. (2009) Effect of Presidential Initiatives on Cassava Production Efficiency in Oyo StateNigeria Ozean Journal f Applied Sciences 2(2), 2009 ISSN 1943-2429 2009 Ozean Publication.

11. Awurum, A.N. (1998) Evaluation of Onion (Album Cepa L.) Cultivars under Rain fed and liTigated Conditions in the Humid Tropics. Journal of Sustainable Agriculture and the Environment Vol.1 No. 1 Edition Umudike pp.56.

12. Bannayan, M., Sadeghi, L.S., Sanjani, S., Mohamadian, A. and Aghaalikhani, M. (2010) Effects of Precipitation And Temperature On Crop Production Variability In North East Iran. International Journal of Biometeorology

13. Blignaut, J., Ueckermann, L. and Aronson, L. (2009). Agricultural Productions sensitivity to changes in climate in South Africa. South African Journal of Science, Vol. 105 no 1-2

14. BNRCC (Building Nigeria's Response to Climate Change) (2012). Learning from Experience-CommunityBased Adaptation to Climate Change in Nigeria. Produced with the Support of the Government of Canada and Canadian International Developing Agency (CIDA) Pp. 16.

15. Craufurda, P.Q., Ellisa, R.H., Porter, J.R. and Prasada, V. (2000) Temperature variability and the yield of Annual crops. Agriculture, Ecosystems and Environment, Vol. 82, issue 1-3, pp. 159167.

16. Dhakhwa G. B., Campbell C. L. (1998), Potential Effect of Differential day-night Warming in Global Climate Change on Crop Production. Climate Change Vol 40, 647-667. 